\title{
Rapid Location of Fish Taste Buds by a Selective Surface Staining Method
}

\author{
Sadao KiYohara, ${ }^{* 1}$ Satoru Yamashita, ${ }^{* 1}$ and Junzoh KitoH ${ }^{* 2}$ \\ (Accepted December 12, 1983)
}

\begin{abstract}
A surface staining of taste buds was studied in the minnow Pseudorasbora parva, carp Cyprinus carpio and blind cave fish Astyanax mexicanus by immersing the tissues in various kinds of staining solutions. The taste pores of buds in the lips, palatal organ and buccal cavity were found to be stained selectively with ponceau $S$ or pontamine sky blue $6 \mathrm{~B}$ dissolved in trichloroacetic acid solutions. In fresh material the dyes were restricted to only the taste pore regions while in fixed material they penetrated deeply into the buds as well as into the general epithelium. This surface staining method enables a rapid location and counting of taste buds without preparing histological sections.
\end{abstract}

Fish have three peripheral gustatory systems: facial, glossopharyngeal and vagal systems. It is well known that the degree of development of the gustatory systems varies considerably among fish with different feeding habits and can be estimated by observing the size of the primary gustatory center in the medulla oblongata. For example, cyprinoid fish have a prominent vagal lobe which is correlated with an enormous number of taste buds in the palatal organ and branchial region. ${ }^{1-4}$ ) In the catfish (Ictaluridae), on the other hand, there is an enlargement of the facial lobe, corresponding to an unusual number of taste buds on the external body surface. ${ }^{5-7)}$ However, the size of the primary gustatory center is not a sufficient indicator of the precise distribution pattern of fish taste buds in the periphery. The distribution of buds has been examined usually by scanning electron microscopy ${ }^{8)}$ or by observing serial histological sections by light microscopy. ${ }^{4}$ )

Besides these routine methods, a surface staining method of taste buds has been established re. cently in higher vertebrates, which enables a rapid location and counting of buds in taste papillae. ${ }^{9,10)}$ For example, Brouwer and WIERSMA ${ }^{10)}$ examined a surface staining of taste buds on the fresh tongue of the monkeny, rat, and frog with various staining solutions, and showed that ponceau $\mathbf{S}$ dissolved in trichloroacetic acid (TCA) solution clearly stained the taste pore of the buds.

In the present study, experiments were performed to apply this surface staining method to fish taste buds using various kinds of staining solutions. The results show that the taste pores in the lips and mouth cavity of fish are also stained selectively with ponceau $\mathbf{S}$ or pontamine sky blue $6 \mathrm{~B}$ dissolved in TCA solution.

\section{Materials and Methods}

The minnow Pseuderasbora parva, carp Cyprinus carpio and blind cave fish Astyanax mexicanus, were used. The fish was anesthetized in $0.002 \%$ MS 222 (tricainemethane sulphonate) for five min. According to the reports which deal with the distribution of taste buds in the above fish, $2,4,11,12$ ) various tissues with a high density of taste buds were removed from the specimen. Included were the barbels (carp), lips, skin of head region, palatal organ, gills and other regions in the buccal cavity.

The t:ssues were briefly rinsed in distilled water (D. W.) and samples were stained with one of the following 19 test solutions;

(1) $0.5 \%$ ponceau $\mathrm{S}$ in (a) TCA $(0.3 \mathrm{M})$ at $\mathrm{pH}$ 0.9 , (b) sodium acetate hydrochloride buffer $(0.1 \mathrm{M})$ at $\mathrm{pH} 2.3$, (c) sodium phosphate buffer (SPB) at pH 7.0;

(2) $1.0 \%$ alcian blue in (a) TCA $(0.3 \mathrm{~m})$ at pH 0.9 , (b) sodium acetate buffer $(0.05 \mathrm{M})$ at $\mathrm{pH} 4.6$, (c) SPB (0.05 M) at pH 7.0;

(3) $0.5 \%$ amido black $10 \mathrm{~B}$ in (a) acetic acid (1.17 M) at pH 0.9, (b) TCA $(0.3 \mathrm{~m})$ at $\mathrm{pH} 0.9$, (c) SPB $(0.05 \mathrm{M})$ at $\mathrm{pH} 7.0$;

(4) $0.5 \%$ pontamine sky blue $6 \mathrm{~B}$ in (a) TCA

*1 Biological Institute, College of Liberal Arts, Kagoshima University, Kagoshima 890, Japan（清原貞夫・ 山下 智：庇児島大学教新部)。

*2 Department of Anatomy, Nagoya University, School of Medicine, Nagoya 466, Japan（鬼頭純三：名古 厤大学医学部). 
$(0.3 \mathrm{M})$ at $\mathrm{pH} 0.9$, (b) sodium acetate buffer $(0.05 \mathrm{M})$ at pH 4.6, (c) SPB $(0.05 \mathrm{M})$ at $\mathrm{pH} 7.0$, (d) barbital sodium hydrochloride buffer $(0.05 \mathrm{M})$ at $\mathrm{pH} 8.2$;

(5) $0.5 \%$ toluidine blue in (a) TCA $(0.3 \mathrm{M})$ at pH 0.9, (b) SPB (0.05 M) at pH 7.0;

(6) $0.5 \%$ erthrosine in (a) TCA $(0.3 \mathrm{M})$ at $\mathrm{pH}$ 0.9 , (b) SPB (0.05 M) at $\mathrm{pH} 7.0$;

(7) $0.5 \%$ cresyl violet in (a) TCA $(0.3 \mathrm{M})$ at pH 0.9, (b) SPB (0.05 M) at pH 7.0.

After staining the tissues were washed in D. W. for $20 \mathrm{~s}$-a few min, observed under a Zeiss type 1 stereomicroscope and photographed with a Nikon Multiphoto. Tissues fixed with $10 \%$ neutral formalin or with an ice cold fixative, which contained $1.6 \%$ paraformaldehyde, $1.6 \%$ glutaraldehyde, $0.08 \mathrm{M}$ SPB and $0.02 \mathrm{~m}$ s-collidine buffer $(\mathrm{pH} 7.3)$, were also examined.

\section{Results}

Among various staining solutions tested, ponceau $S$ in TCA and pontamine sky blue 6B in TCA were the most effective in visualizing the taste buds of minnow, carp and blind cave fish. When a fresh minnow upper lip bearing the respiratory valve was immersed in ponceau $S$ or pontamine sky blue $6 \mathrm{~B}$ in TCA solution for $20 \mathrm{~s}$ and briefly washed in D. W., a number of fine red or blue dots were observed on the dorsal surface of the valve under a stereomicroscope, as seen in Plates 1 and 2. These dots varied in diameter from 14 to 25 $\mu \mathrm{m}$. Plate 3 is a partially enlarged photograph of the surface of the valve stained with ponceau $S$ in TCA, clearly indicating that each red dot corresponds to the pore region of the taste bud (also. see plate 4). The rest of the epithelium was hardly stained. Plate 4 is a photograph of a frozen section across the respisatory valve stained with ponceau $\mathrm{S}$ in TCA. As shown in this plate, the dye did not penetrate deeply into the buds; it was restricted to only the taste pore region.

Plates 5 and 6 show the surface of the palatal organ of minnow and that of the buccal mucosa adjacent to the lower lip, which were treated with ponceau $\mathrm{S}$ in TCA and pontamine sky blue $6 B$ in TCA, respectively. A number of colored dots with a diameter of 12-27 $\mu \mathrm{m}$ became visible after $20 \mathrm{~s}$ immersion in the staining solutions. They were distributed along the top of the epidermal ridges but not on the rest of the epithelium. These distribution patterns of colored dots in the mucosa of the mouth cavity are in agreement with those of the taste buds observed in the same re- gion within the serial histological sections." In the carp and blind cave fish also, the lip region taste buds were rather selectively stained with the above two dye solutions.

External and branchial taste buds in the minnow, carp and blind cave fish were also stainable with ponceau $S$ in TCA or pontamine sky blue $6 \mathrm{~B}$ in TCA However, the visibility of these buds was somewhat inferior to that of the lip region taste buds, since the surface of the general epithelium also reacted to some extent with the dyes.

Alcian bluc in sodium acetate buffer and erythrosine in TCA weakly stained the taste buds in the lip region of the three species of fish. The other staining solutions listed in the previous section failed in staining selectively the taste buds of various tissues. For example, ponceau S in SPB and pontamine sky blue $6 \mathrm{~B}$ in SPB without TCA stained neither the taste buds nor the epithelium while amido black in acetic acid and cresyl violet in TCA unselectively reacted on the entire surface of the tissues.

In contrast to the fresh tissues, the fixed tissues were not suitable for the selective staining of taste bud pores. The whole epithelial surface of the fixed tissues was strongly colored with ponceau $\mathbf{S}$ or pontamine sky blue in TCA or SPB. Light mi-roscopical observation of frozen sections which were made after $20 \mathrm{~s}$ immersion of the minnow lip in ponceau $S$ in TCA showed that the dye penetrated deeply into the buds as well as into the general epithelium of the fixed tissues.

The surface staining method described above is convenient to locate and count taste buds of fish rapidly. Using this method, the number of taste buds on the minnow respiratory valve was counted in 142 specimens of various sizes. The results are summarized in Fig. 1. The figure reveals that the number of taste buds on the respiratory valve of the minnow tends to increase in proportion to an increase in body length as expected from the results obtained in other species of fish. ${ }^{13)}$ It also shows that the number varies considerably even among fish of the same size. This variation confirms our previous histological observation,") suggesting that besides the size of fish and possibly its age there are other factors, as has been pointed out previously,") on which the number of taste buds is dependent.

\section{Discussion}

Our staining tests reveal that ponceau $S$ in TCA 


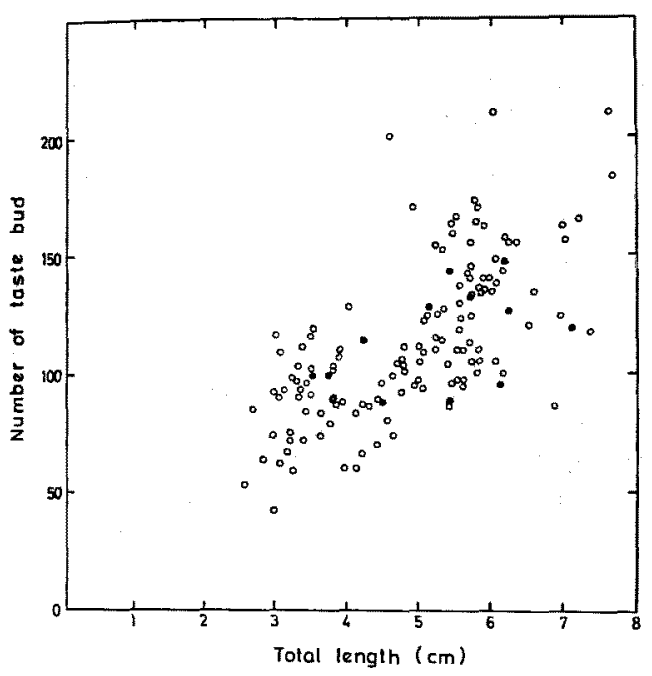

Fig. 1. Relation between the number of taste buds located on the minnow respiratory valve and the body length of the minnow. Taste buds were counted under a dissecting microscope after the valve was stained with ponceau $S$ in TCA (open circles) or by scanning electron microscopy with unstained tissue (solid circles).

and pontamine sky blue $6 \mathrm{~B}$ in TCA stain strongly the pore region of taste buds in various tissues of minnow, carp and blind cave fish (Plates 1-6). This staining technique provides a simple and rapid method to locate and count the taste buds in fish as demonstrated in Fig. 1. The ability of the two dyes to stain seems to be uniform among different location of taste buds. But visibility of the taste pores varies depending on the stainability of the epithelial surface with the dyes.

Similar staining methods have been established in higher vertebrates and it was found that the above two dyes were also effective. ${ }^{9,10)}$ For example, pontamine sky blue in sodium acetate buffer ( $\mathrm{pH} 8.3$ ) visualized the fresh or fixed taste buds in the bill of mallard, but this staining solution was not effective in the fish taste buds. According to histochemical examinations, it is thought that the dye reacts with neutral mucopolysaccharides in the inner pore region between the apical ends of taste bud cells. ${ }^{2)}$ Ponceau $S$ in TCA visualizes clearly the taste buds on the fresh tongue of monkey, rat, and frog. The proteinaceous substances contained in the extracellular material of the taste pit are responsible for the strong reaction with the dye, since it is a highly acidic protein dye and treatment of the tongue with proteinase reduces this reaction. ${ }^{10)}$ Therefore, it is conceiv- able that pontamine sky blue $6 \mathrm{~B}$ and ponceau $\mathrm{S}$ react with neutral mucopolysaccharides and proteinaceous substances, respectively, to visualize the fish taste buds.

The limited localization of the staining dye in the apical portion of minnow taste buds (Plate 4) indicates that the reacting substances are located in the apical region rather than in the other region of taste buds. Two types of apical processes of taste bud cells are reported in various species of fish. ${ }^{14-17)}$ One is a thick rod-shaped apical process of $t$-cell or light cell and the other is microvilli of f-cell or dark cell. Between these apical processes there is usually extracellular material or mucus which is thought to be derived from the secretory granules of $\mathrm{f}$-cells. ${ }^{17}$ ) In the minnow, ${ }^{187}$ this material contains disk-shaped bilaminar fragments which are not seen on the surface of the general epithelium and which are quite similar to those seen in the taste buds of the axolotl Ambystoma mexicanum. ${ }^{\left.1{ }^{19}\right)}$ ReUTteR, ${ }^{20)}$ applying different methods for preserving the mucus for scanning electron microscope, carefully examined the mucous layer on the surface of catfish taste buds. He suggested that the rod-shaped processes possess only a very thin, if any, mucous coat, while the microvilli are completely covered with the surface coat. Further experiments are necessary to elucidate which part of the apical region of fish taste buds the effective dyes stain. In higher vertebsates, it has been reported that the dyes stain the extracellular material rather than the protruding tips of the taste bud cells. ${ }^{0,21)}$

\section{Acknowledgements}

We wish to thank Drs. I. HidaKa, Mie University, and $\mathbf{J}$. CAPrio, Louisiana State University, for valuable comments on the manuscript. We are also indebted to Miss K. SAKo for her technical assistance.

\section{References}

1) C. J. Herrick: J. Comp. Neurol., 15, 375-456 (1905).

2) T. IWaI: Bull. Misaki Mar. Bio. Inst. Kyoto Univ., 7, 19-34 (1964).

3) P. G. M. Luiten: J. Comp. Neurol., 160, 399418 (1975).

4) S. KiYoharA, S. YamashitA, and J. KITOH: Physiol. Behav., 24, 1143-1147 (1980).

5) C. J. Herrick: J. Comp. Neurol., 11, 177-249 (1901). 
6) J. AtEma: Brain Behav. Evol., 4, 273-294 (1971).

7) T. E. Finger: J. Comp. Neurol., 165, 513-526 (1976).

8) K. Reutter, W. Breipohl, and G. J. Bijvank: Cell Tiss. Res., 153, 151-165 (1974).

9) H. Berkhoudt: Neth. J. Zool, 27, 310-331 (1977).

10) J. N. BrouWer and A. Wiersma: Histochemistry, 58, 145-151 (1978).

11) C. SChemmel: Z. Morph. Ökol Tiere, 61, 255316 (1967).

12) K. Kawakita, T. Marui, and M. Funakoshi: Jap. J. Oral Biol., 20, 103-113 (1978).

13) H. Campos: Z. wiss Zool., 179, 253-299 (1969).

14) J.-C. Desgranges: C. R. Hebd. Seanc. Acad. Sci., 261, 1095-1098 (1965).

15) Y. HiRata: Arch Histol, Jap., 26, 507-523 (1966).
16) M. Crisp, G. A. Lowe and M. S. Laverack: Tissue Cell, 7, 191-202 (1975).

17) N. Grover-Johnson and A. I. Farbman: Cell Tiss. Res., 169, 395-403 (1976).

18) S. KTYohara, S. Yamashita, and J. Kitoh: in "Olfaction and Taste VII" (ed. by VAN DER STARRE), IRL Press Ltd. London \& Washington DC, 1980, p. 204.

19) M. WhiteAR: Cell Tiss. Res., 172, 389-404 (1976).

20) K. ReUTter: in "Olfaction and Taste VII" (ed. by VAN Der Starre), IRL Press Ltd. London \& Washington DC, 1980, p. 107.

21) J. N. BrouWer and A. WIERSMA: in "Olfaction and Taste VII" (ed. VAN DER STARre), IRL Press Ltd, London \& Washington DC, 1980, pp. 179182.

Plate 1. Surface view of the minnow respiratory valve after staining with ponceau S in TCA. Taste buds are visible as colored dots on the surface. The minnow's upper lip bearing the respiratory valve was stained for 20 s and washed in D. W. $\times 60$

Plate 2. Surface view of the minnow respiratory valve after staining with pontamine sky blue $6 \mathbf{B}$ in TCA. $\times 50$

Plate 3. Partially enlarged view of the minnow respiratory valve after $20 \mathrm{~s}$ staining with ponceau $S$ in TCA. The dye is located in the pore region. $\times 150$

Plate 4. Cross section through the minnow respiratory valve. The section was made after the upper lip was stained for $20 \mathrm{~s}$ with ponceau $\mathrm{S}$ in TCA and was quickly frozen. The dye is localized in the taste pore region of taste buds. $\times 200$

Plate 5. Surface view of the minnow palatal organ after staining with ponceau $\mathbf{S}$ in TCA. Taste buds are present on the epidermal ridges. $\times 50$

Plate 6. Surface view of the buccal mucosa adjacent to the lower lip after $20 \mathrm{~s}$ staining with pontamine sky blue $6 \mathrm{~B}$ in TCA. Taste buds are present on the epidermal ridges. $\times 40$ 
Plate 1 Plate 6
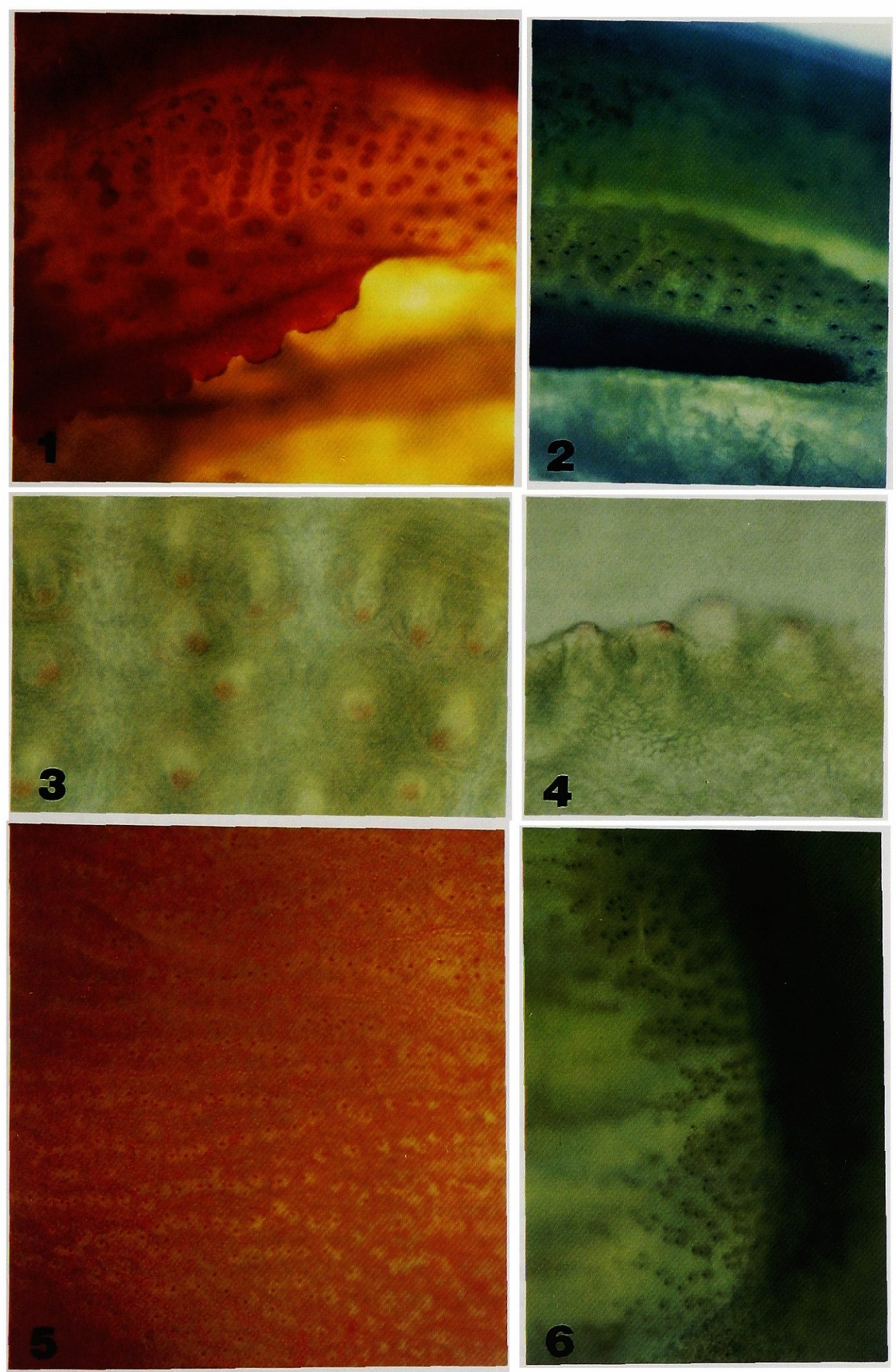